'llu. Revista de Ciencias de las Religiones

ISSN: $1135-4712$

http://dx.doi.org/10.5209/ILUR.57426

\title{
La Inmaculada Concepción en España. Un estado de la cuestión
}

\author{
David Martínez Vilches ${ }^{1}$
}

Recibido: 23 de julio de 2016 / Aceptado: 29 de noviembre de 2016

Resumen. Este artículo presenta las principales aportaciones que se han hecho desde la historia y las ciencias sociales al estudio de la Inmaculada Concepción en España. Se aplica la clásica división entre historia eclesiástica e historia de la Iglesia para realizar un análisis diacrónico de la bibliografía sobre este tema, atendiendo tanto al desarrollo de la narrativa/investigación histórica como a los contextos por los que esta atraviesa. Este análisis se plantea como estudio de caso para mostrar la evolución de los estudios históricos sobre la Iglesia y la religión, así como su actual riqueza temática y metodológica. Palabras clave: Inmaculada Concepción; devoción mariana; estado de la cuestión; historia religiosa.

\section{[en] The Immaculate Conception in Spain. The state of the question}

\begin{abstract}
This article presents the main contributions made from History and Social Sciences in the study of the Immaculate Conception in Spain. The classic division between Ecclesiastic History and Church History is applied to carry out a diachronic analysis of the bibliography on this issue, taking into account both historical narrative/research's development and the different contexts it goes through. This analysis is set out as a case study in order to show the evolution of historical studies on the Church and religion and their thematic and methodological possibilities nowadays.
\end{abstract}

Keywords: Immaculate Conception; Marian devotion; state of the question; Religious History.

Sumario. 1. Introducción. 2. Historia eclesiástica. 3. Historia de la Iglesia e historia religiosa. 3.1. Historia de las relaciones internacionales. 3.2. Estudios iconográficos. 3.3. Historia de las mentalidades, antropología religiosa y estudios de género. 4. Conclusión. 5. Bibliografía.

Cómo citar: Martínez Vilches, D. (2017), La Inmaculada Concepción en España. Un estado de la cuestión, en 'Ilu. Revista de Ciencias de las Religiones 22, 493-507.

\section{Introducción}

El tema de la Inmaculada Concepción -ya sea como misterio, celebración litúrgica, advocación religiosa o dogma - ha sido abordado por la historiografía desde distintas perspectivas, a partir de diferentes metodologías y con resultados muy variados, tanto cuantitativa como cualitativamente. En este trabajo hemos realizado un breve recorrido por la bibliografía española, desde el siglo XVIII hasta nuestros días, que 
se ha ocupado de esta cuestión en el campo de la historia, así como de otras disciplinas adyacentes en el conjunto de las ciencias sociales. Un desarrollo cronológico tan lato nos muestra cómo un mismo objeto de estudio ha sido tratado de forma muy distinta a lo largo del tiempo, en función de la propia dinámica de la investigación histórica, pero también de los distintos contextos que esta atraviesa. Por otro lado, aunque nuestra atención privilegie las publicaciones nacidas en España, no podemos desatender otras aportaciones extranjeras, en tanto que nos sirven para establecer horizontes comparativos entre la historiografía española y otras.

Para analizar y evaluar esta masa de literatura secundaria se nos plantea desde el principio un problema fundamental: el de la ordenación sistemática de la misma. Una distinción básica y consolidada en todos los estudios que se han ocupado de la Iglesia católica en una dimensión diacrónica ha sido la oposición entre historia eclesiástica e historia de la Iglesia. Se entiende por historia eclesiástica un género histórico que presenta una narración del pasado como evidencia probatoria de la verdad revelada por la religión, escrita con unos fines clericales o religiosos y con tintes claramente teológicos. Por el contrario, la historia de la Iglesia es un género historiográfico que ofrece las características propias de un conocimiento histórico estrictamente científico, esto es, causal, crítico y objetivo. Dentro de este hallamos como subgénero la historia religiosa, que implica el paso del relato de las instituciones eclesiásticas hacia el análisis de todo aquello que implica la religión en un sentido extenso y, sobre todo, cultural ${ }^{2}$.

\section{Historia eclesiástica}

En 1776 el sacerdote ilustrado Fernando Ramírez de Luque publicó un estudio sobre la Inmaculada Concepción. El carácter regalista del reinado de Carlos III le impelió a coger la pluma y redactar una Historia de los hechos, y escritos del clero secular en defensa, y honor de la Concepción Inmaculada de María Santísima ${ }^{3}$. En ella Ramírez de Luque utilizaba una abundante documentación eclesiástica para probar el concurso del clero secular en la defensa y el patrocinio de la creencia inmaculista. No es casualidad la elección del autor por una advocación especialmente venerada por los sectores populares, que, a su vez, había sido elevada al rango de «Patrona Universal de los Reinos de España e Indias» en 1761 por el mismo rey que dos años antes había ordenado la expulsión de Madrid de los religiosos que no tuviesen expreso consentimiento de sus superiores, y seis años después la salida de todos los jesuitas de los territorios de su monarquía. Lo que pretendía el sacerdote lucentino era hacer ver la sintonía entre el estamento religioso y la devoción personal del monarca reinante, así como la de sus súbditos, poniendo en evidencia la contradicción de la política regalista. Aunque el manejo de la documentación es cuidadoso y crítico, pesan más las intenciones clericales del autor, que vierte algunas nociones que serán recogidas por la historia católico-conservadora.

\footnotetext{
2 Sobre la historia religiosa hay una bibliografía abundante y preferentemente francesa, pues ha sido la historiografía gala la que más temprano desarrolló este ámbito de estudio. Vid. Langlois - Vauchez 1995; Durand 2009; Montero 2015.

3 Ramírez de Luque 1776.
} 
Si Ramírez de Luque mencionaba España, no era más que para destacar al clero español sobre el de otros reinos. Todavía no existía una formulación en clave nacional-católica, incluso aunque aparezca el término nación ${ }^{4}$. Así, por ejemplo, cuando Juan Francisco Masdeu escribía que «La Concepción purísima de la Madre de Dios [...] es gloria particular de la nación Española ${ }^{5}$ se refería al clero, concretamente al clero del reino visigodo de Toledo, subrayando el arraigo de esta advocación en el clero hispano. Efectivamente, todavía en el siglo XVIII se hablaba de nación en un estricto sentido etimológico para referirse a quienes tenían la misma procedencia por su nacimiento (del latín natus, participio pasado de nascor, «nacer»), lo que aplica un carácter étnico al término, pero no político. En cualquier caso, se iba forjando una idea de que unía el catolicismo con ese carácter étnico, que años después seducirá primero a la historia católico-conservadora y a la nacional-católica después.

Esa idea acabará consolidándose con la Guerra de la Convención y la Guerra de la Independencia, que tendrán importantes consecuencias impulsando la identificación entre comunidad de creyentes y esa comunidad étnica convertida con la Constitución de 1812 en nación. La religión jugó un papel fundamental a la hora de cohesionar un sujeto colectivo y movilizarlo en armas frente al invasor y, a su vez, asemejar las comunidades religiosa y política con un sentido de pertenencia excluyente hacia otras comunidades nacionales vecinas. La Inmaculada Concepción, misterio ya tan identificado con la monarquía que la invasión napoleónica había puesto en jaque, volvió a esgrimirse como símbolo, ahora nacional, por parte de los «patriotas» frente al francés invasor. Así lo podemos observar en los juramentos que debían ser pronunciados por los miembros de las juntas provinciales, uno de los cuales consistía en la defensa de esta advocación. O, por poner otro ejemplo, en un despacho al presidente de la Junta Central:

Serenísimo Señor:

Desengañémonos: mientras no pongamos nuestra confianza en Dios y su Madre no esperemos conseguir victoria de nuestros enemigos. Los males que estamos padeciendo es justo castigo de nuestros pecados. Enmendémonos y hagamos penitencia, y que sea esta pública, pues por los pecados públicos vienen los castigos públicos, y de este modo aplacaremos la ira de Dios y se compadecerá de nosotros, y levantará el azote de su divina justicia. Haga Vuestra Alteza voto (como ya se lo han aconsejado) a nombre de nuestro amado Rey Fernando $7^{\circ}$ de solicitar la canonización del Misterio de la Concepción de la Virgen. Pues está revelado que ha de llegar tiempo [en] que este dulce Misterio se ha de celebrar en la Iglesia como mysterio de fe. A[h]ora es el tiempo: pues a un beneficio grande, debe preceder una calamidad y tribulación grande: [¿]yquál puede ser mayor? Eso Vuestra Alteza

4 En última instancia, el patronato de la Inmaculada declarado por Carlos III era un símbolo más dinástico que nacional, que asimismo pretendía minimizar los derechos del cabildo compostelano a cobrar el voto de Santiago. Álvarez Junco 2015, 71, 163, n. 47. El texto del decreto del Universal Patronato de la Inmaculada se recoge en la Novísima Recopilación 1805, lib. I, tít. I, ley XVI. Esta advocación también sería la patrona de la Real y Distinguida Orden Española de Carlos III, establecida en septiembre de 1771 con motivo del nacimiento del primer hijo del príncipe Carlos. En 1779, en esta Real Orden se integraría la Real Junta de la Inmaculada, que desde el siglo XVII se encargaba de la promoción de este misterio como dogma (Novísima Recopilación, 1805, lib. I, tít. I, ley XIX).

$5 \quad$ Masdeu 1792, 211. 
lo puede considerar mejor que yo. No molesto más a Vuestra Merced. Nuestro Señor dé acierto en todo y a todos como se lo pido. Etc., etc. ${ }^{6}$

Todas estas construcciones en clave nacional tuvieron su influencia en las obras de los historiadores del siglo XIX, especialmente en los que se adherían a la vertiente católico-conservadora. Estos escritores, conscientes de los cambios generados por la quiebra del Antiguo Régimen y el establecimiento del Estado liberal -y de todos los conflictos que de ello se derivaban, empezando por las relaciones entre dicho Estado y la Iglesia-, escribieron sus narraciones proyectando las necesidades identitarias de las construcciones nacionales de la época. Se trataba de diseñar, a partir de la compleja pluralidad del pasado, un relato que subrayase la singularidad del colectivo nacional, en el sentido que Eric Hobsbawm y Terence Ranger han denominado como «invención de la tradición» o en el que Benedict Anderson ha señalado al definir las naciones como «comunidades imaginadas» ${ }^{7}$. La unión sustancial entre nación -en los carlistas, sin embargo, todavía patria- y religión católica era el núcleo de dichas construcciones identitarias para liberales moderados, neocatólicos y carlistas. En ello la devoción a la Inmaculada, dentro de la devoción mariana en general, jugaba un papel fundamental al evidenciar la predilección de España por la Virgen y viceversa.

La definición dogmática de la Inmaculada en 1854 vendría a galvanizar -incluso con un tono contrarrevolucionario añadido- estos discursos. En textos como los de Basilio Sebastián Castellanos de Losada, Joaquín Roca y Cornet o Víctor Gebhardt se subrayaba el temprano fervor inmaculista en España, al margen de cualquier evidencia probatoria ${ }^{8}$. Polígrafos y publicistas católicos venidos a historiadores citaban como fuentes el breviario de Isidoro de Sevilla aprobado en el IV Concilio de Toledo (633) y los textos de san Ildefonso («el capellán de María»). Confundían en el primer caso el breviario original del arzobispo hispalense con el editado por Cisneros y, en el segundo, la virginidad de María -que sí defendió Ildefonso- con su concepción inmaculada. Claro está que a estos escritores no les interesaba la veracidad histórica ni la exactitud conceptual en sus afirmaciones, sino la identificación políticoreligiosa de su contenido.

La explosión de fervor a la Inmaculada en el siglo XIX -tanto antes como después de la proclamación dogmática- no solo afectó a España. El clero francés recibió con gran entusiasmo la bula de 1854, habida cuenta de que en su territorio se había producido una supuesta aparición mariana específicamente inmaculista, la de la Virgen de la Medalla Milagrosa a Catherine Labouré en 1830, cuya devoción adquirió una elevada popularidad en muy poco tiempo. La obra que el cardenal Gousset publicó un año después de la bula papal refleja este interés por afirmar que «la creencia de la Iglesia en la Concepción pura y santa de la Gloriosa Virgen María, Madre de Dios, no es ninguna creencia nueva; tan antigua que es general, tan antigua como

6 Archivo Histórico Nacional, Estado, leg. 52-H, exp. 410. Los juramentos de las juntas provinciales se recogen en la prensa de la época, p. ej.: Diario de Madrid, 21-VIII-1808, 60-61, para el de la junta del Principado de Cataluña. También un diputado a las Cortes de Cádiz, el sacerdote guatemalteco Antonio de Larrazábal, propuso el 16 de octubre de 1811 que el voto de defensa de la Inmaculada se extendiera al juramento a la Constitución que Fernando VII habría de hacer cuando regresase al acabar la guerra. Diario de las discusiones y actas de las Cortes de Cádiz 1811, 303-304.

7 Hobsbawm - Ranger (eds.) 2002; Anderson 1993.

8 Castellanos de Losada 1855; Roca y Cornet 1856; Gebhardt 1864, 192. 
el cristianismo» ${ }^{9}$. Tres años después de que apareciesen impresas estas palabras se producía otra supuesta aparición de la Inmaculada en Francia, esta vez en Lourdes, a Bernadette Soubirous. En cualquier caso, hay que señalar una diferencia esencial que se distingue en estos libros que están más cerca de la publicística que de la historia entre España y Francia. Mientras que en el caso español el componente patriótico o nacional es evidente, en el caso francés eso no sucede. Esto es explicable debido al diferente componente religioso que tuvo la cultura política liberal en ambos países: mientras que en Francia la secularización fue un elemento central de los sucesivos gobiernos liberales, en España se produjo una identificación entre nación española y catolicismo a la caída del Antiguo Régimen, sancionada después por la sucesiva legislación, exceptuando el paréntesis del Sexenio Democrático ${ }^{10}$.

El quincuagésimo aniversario de la proclamación dogmática, en 1904, fue otro momento propicio para que los que miraban al pasado con una óptica -ahora sínacional-católica, sacasen a relucir la devoción a la Inmaculada. Una cita de la obra de un jesuita español de la época sintetiza de forma clara estos postulados:

¿No había de amar el pueblo español a la Virgen, que, desde que vino en carne
mortal a Zaragoza, fue siempre para España la más cariñosa de las madres, con un
amor tan peculiar que, bien podemos decir, sin ofensa de madre, que no hizo tal
con otras naciones, non fecit taliter omni nationi? [...] El pueblo español revelren-
ció [sic] tanto la Concepción Inmaculada de la Virgen María, porque amaba a esta
celestial Señora con amor verdaderamente filial, y así imposible se le hacía ver una
mancha en la que amaba como a madre. ${ }^{11}$

No obstante, de mucho más interés, tanto por su autor como por su contenido, es el discurso pronunciado por Marcelino Menéndez Pelayo el 5 de diciembre de 1904 en el Museo Provincial de Bellas Artes hispalense. En él, el intelectual conservador por excelencia desarrolla una teoría de la estética barroca española en la que lo sustancial es la esencia trascendental católica, y que se manifiesta de forma inequívoca en la afirmación del misterio de la Inmaculada ${ }^{12}$. Autores anteriores, como Servando Arbolí Faraúdo o Ángel Ganivet, habían hecho una lectura de la advocación inmaculista en clave cultural, ${ }^{13}$ pero es Menéndez Pelayo quien mejor la formula. Por el tono del texto y sus referencias históricas, es evidente la pesadumbre causada por el 98, de forma que mitifica y mistifica un pasado imperial contrarreformista donde arte y literatura expresan el discurso ideológico católico que tiene como su centro a la Inmaculada. En cualquier caso, adelantándose décadas al estudio antropológico de los símbolos religiosos, el escritor cántabro exploraba a través de la Inmaculada «aquellas intuiciones del mundo real que le trasfiguran simbólicamente y nos hacen leer en el símbolo conceptos de transcendental sabiduría; aquella visión mágica de la naturaleza, que nos penetra y envuelve lánguidamente y se asocia por recóndita simpatía con los estados de nuestra alma». ${ }^{14}$ De alguna manera, y aceptando por supuesto

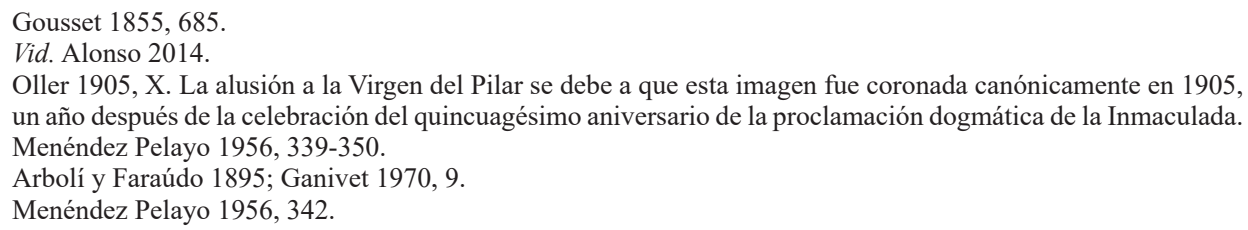


ciertas reservas, el escritor cántabro se adelantaba a Clifford Geertz al señalar que los símbolos religiosos articulan el carácter propio de una sociedad y la visión de la realidad que tiene, de forma que ambos se hacen coincidentes y se perpetúan como elementos opuestos al cambio social.

Encontramos también a principios de siglo una literatura que hace una lectura militarista del misterio y dogma de la Inmaculada, Patrona del Arma de Infantería Española desde 1892. Se trata de un período de efervescencia religiosa abierto por la Restauración borbónica, e intensificado durante el reinado de Alfonso XIII en una línea integrista, a lo que además se suma la impregnación devocional bélica procedente de la Gran Guerra. Así, al nombramiento del patronato de la Inmaculada para la Infantería de 1892 le seguirán los de la Virgen del Carmen para la Armada en 1901, la Virgen del Pilar para la Guardia Civil en 1913 y Nuestra Señora del Loreto para la Aviación en 1920; sin olvidar la consagración de España al Sagrado Corazón de Jesús en 1919 y la coronación de la Virgen de Guadalupe como «Reina de las Españas» en $1928^{15}$. Ejemplos de esa literatura son las obras de militares como Antonio García Pérez y Alfredo Serrano Durán ${ }^{16}$. La añoranza hacia el pasado imperial de los Tercios - con el supuesto milagro de Empel de 1585 como prueba irrefutable de la toma de partido de la Inmaculada por las tropas españolas-, así como el servicio del estamento militar a un particular concepto de orden social inextricablemente unido a la religión y a la patria son sus características más notables.

Continuando en el tiempo, la Guerra Civil española y la larga dictadura instaurada por Franco, primero en la zona rebelde y después en el resto de España, propiciaron un uso de la Inmaculada como símbolo nacional por parte de la reacción autoritaria del estamento militar y la jerarquía eclesiástica, en pos de un proceso de recatolización violento contra el laicismo republicano anterior. No en vano, el primer decreto relativo a festividades en la España franquista fue el del 6 de diciembre de 1936, que declaraba como festivo el día de la Inmaculada «interpretando el espíritu tradicional del pueblo español», según el texto del decreto ${ }^{17}$. Todo ello, como señala Zira Box, «suponía la reafirmación de los favorables designios que la Virgen tenía preparados para los soldados nacionales $\rangle^{18}$. En este contexto, el breve escrito de Ricardo Pérez Fernández, La Inmaculada Concepción, Patrona de la Infantería Española, actualiza los planteamientos ideológicos integristas anteriores tomando en cuenta la situación bélica ${ }^{19}$.

La celebración del centenario de la proclamación dogmática en 1954 será otro momento de exaltación de la Inmaculada. Obviando la continuación de la línea nacional-católica, explicada ya con los ejemplos anteriores, hemos de señalar la obra póstuma de Nazario Pérez, La Inmaculada y España, que implica un giro renovador desmarcado en gran medida de las narraciones clericales del momento ${ }^{20}$. Su autor, un palentino jesuita en contacto con la corriente de erudición documental desplegada dentro de la historiografía eclesiástica desde el siglo XIX, proporciona una síntesis descriptiva de la devoción inmaculista en España sustentada en fuentes primarias

\footnotetext{
15 Vid. Cano 2009; Pérez Frías 2005; Pérez Frías 2012. Sobre la dimensión religiosa de la Primera Guerra Mundial vid. Jenkins 2014

García Pérez 1905 y 1912; Serrano Durán 1905.

Decreto $n^{\circ} 96$ de 6-XII-1936, BOE, nº 51, 9-XII-1936, 355.

Box 2010, 202 (cursiva de la autora).

Pérez Fernández 1937.

Pérez 1954. Sobre este autor vid. Escalera 2001.
} 
que son criticadas y verificadas. Así, alerta contra los textos heredados por la tradición de la Iglesia que contradicen la cronología asumida por los estudiosos, y pone énfasis en los distintos contextos a través de los cuales atraviesa la devoción a la advocación de la Inmaculada. No obstante, no pudo sustraerse del contexto político de su época, como evidencian algunos pasajes: el tratamiento del regalismo de Carlos III, afirmando que la consecución del Patronato de 1761 se debe a la Junta de la Inmaculada y a las Cortes pero no al monarca; el enjuiciamiento negativo del Bienio Progresista de 1854-1856, cuando se produjo la declaración dogmática; o, lo más sorprendente, el excurso que hace sobre la ayuda que la Inmaculada pudo prestar a las tropas rebeldes sitiadas en el Alcázar de Toledo en el verano de 1936.

Pasados los años, los cambios políticos y las transformaciones dentro de la Iglesia han propiciado que la historiografía eclesiástica se haya depurado de los excesos anteriores y haya adoptado, en su mayoría, las conclusiones de la historiografía científica, al tiempo que historiadores profesionales han participado en muchos de los encuentros científicos albergados por instituciones eclesiásticas. Un ejemplo esto es el Instituto Escurialense de Investigaciones Históricas y Artísticas, de la Orden de los Agustinos, pero vinculado como centro adscrito a la Universidad Complutense, que con motivo del $150^{\circ}$ aniversario de la proclamación del dogma de la Inmaculada en 2004 organizó un simposio al año siguiente que albergó multitud de aportaciones, desde muy distintos enfoques ${ }^{21}$. O, en un sentido similar, el XV Simposio de Historia de la Iglesia de España y América, que, por el mismo motivo, se tituló La Inmaculada y Sevilla, éste con un sentido más religioso que el anterior, pero en el que también tuvieron cabida investigaciones históricas ${ }^{22}$. Tampoco faltan autores eclesiásticos que hayan sabido conjugar armónicamente sus creencias con un tratamiento objetivo y documentado del tema ${ }^{23}$.

\section{Historia de la Iglesia e historia religiosa}

Los primeros que trataron la cuestión de la Inmaculada con rigor y solvencia fueron sacerdotes preocupados por lo que los textos cristianos antiguos y la tradición posterior recogían acerca del misterio de la concepción de María sin mancha de pecado. En este sentido, se observa una línea de continuidad desde el siglo XVIII hasta el siglo $\mathrm{XX}$, con distintos estudiosos que recogieron y analizaron fuentes primarias para establecer la historia de la advocación de la Inmaculada Concepción. Uno de los primeros fue el jesuita Benedetto Plazza, que en su obra de 1747 coteja desde textos de los evangelios hasta documentos eclesiásticos de muy distinta época. «No parece pequeña empresa disponer todas las cosas en su lugar apropiadamente y asignarlas a sus épocas: hay que suprimir las inútiles, desechar las falsas, confirmar las verdaderas, sacar a la luz las escondidas, extraer todas precisamente de sus propias fuentes», advierte al lector en sus primeras páginas, expresando la importancia que la historiografía ilustrada otorgaba a la erudición documental ${ }^{24}$. Un trabajo similar es el que realizó el franciscano Marc Antoine Gravois, centrándose en la propagación

\footnotetext{
Campos (ed.) 2005.

Castañeda Delgado - Cociña y Abella (eds.) 2007.

Ros 1994; Ros 2013.

Plazza 1747, V.
} 
de la festividad de la Inmaculada ${ }^{25}$. Esta tendencia fue seguida posteriormente por el jesuita Antonio Ballerini, que con motivo de la proclamación dogmática realizó una magna labor de recopilación y contraste de textos ${ }^{26}$, y, ya en la primera mitad del siglo XX, por el asuncionista francés Martin Jugie, estudioso del misterio de la Inmaculada en la Iglesia de Oriente ${ }^{27}$.

No obstante, lo que nos interesa ahora es reseñar las últimas aportaciones que desde el campo de la historia, así como desde las ciencias sociales en general, se han hecho al tratamiento del tema. Dividimos nuestro análisis en tres partes: primero las publicaciones sobre historia de las relaciones internacionales; segundo, la bibliografía sobre iconografía; y tercero, las contribuciones realizadas desde la historia de las mentalidades, la antropología histórica y los estudios de género, que podemos agrupar en un mismo bloque. Esta diferenciación tripartita cubre bien toda la literatura secundaria relativa al tema.

\subsection{Historia de las relaciones internacionales}

Las negociaciones que la Monarquía de los Habsburgo madrileños mantuvo con la Santa Sede ha sido un tema privilegiado, en base a una abundante documentación que existe en los archivos españoles. Esta documentación se puede dividir en dos bloques: la generada en la Junta creada en 1652 por Felipe IV para conseguir de Roma la proclamación dogmática, en el Archivo Histórico Nacional ${ }^{28}$, y la que está en el Archivo del Ministerio de Asuntos Exteriores; asimismo, hay que hacer constar la disponible en el Archivo Secreto Vaticano. Las relaciones diplomáticas entre España y Roma en torno a una posible definición dogmática de la Inmaculada es un campo que empieza a desbrozar en la década de 1930 el erudito franciscano Josep Maria Pou i Martí y, ya en la década de 1950, coincidiendo con el concordato entre España y la Santa Sede en 1953 y el centenario de la definición dogmática en 1954, es retomado su estudio con trabajos como los de C. M M $^{\text {A }}$ bad, Juan Meseguer, Constancio Gutiérrez e Isaac Vázquez ${ }^{29}$. No obstante, faltaba una integración de toda esa información diplomática en un conjunto más amplio de las relaciones internacionales.

A este respecto, es destacable el estudio de Paolo Broggio, que, centrándose en la diplomacia del siglo XVII anterior a Carlos II, ha analizado cómo convertir esta disputa teológica en cuestión de Estado sirvió a la Monarquía Hispánica para intervenir en los asuntos eclesiásticos ${ }^{30}$. A partir de la documentación diplomática, este autor sostiene que, mientras que los Habsburgo insistían en la proclamación dogmática, Roma no terminaba de decidirse a tomar parte en la disputa entre maculistas e inmaculistas, habida cuenta de que su posicionamiento en un bando podía soliviantar al otro y, lo que era más preocupante, menoscabar la autoridad dogmática de la propia sede pontificia, que durante siglos había rehusado tomar parte en la querella. Esta ambigüedad fue aprovechada por la Monarquía Católica para sancionar su interven-

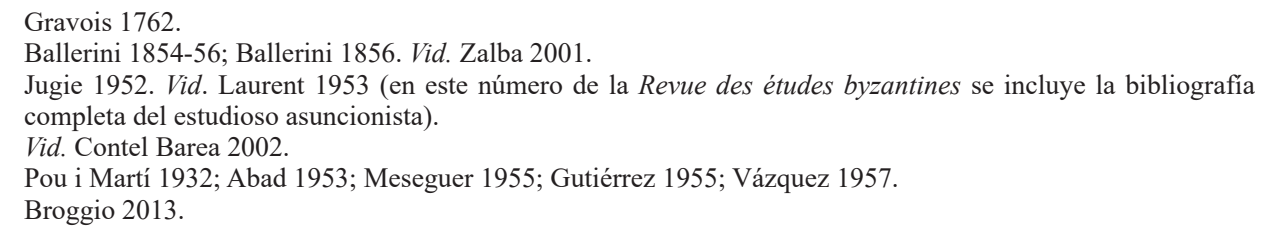


ción en asuntos eclesiásticos como un privilegio derivado de su postura como primer adalid de la Contrarreforma.

Un trabajo de síntesis reciente es el José Antonio Peinado Guzmán, que abarca toda la actividad diplomática en la Edad Moderna relacionada con la proclamación dogmática de la Inmaculada ${ }^{31}$. En nuestra opinión, parte de un error al afirmar que la labor de los Habsburgo estribaba en una mediación entre sus súbditos y la Santa Sede, pues la devoción popular no fue el factor de peso, sino que el motor fueron los propios intereses políticos de la Monarquía Hispánica, con el intento de erigirse en entidad política preferente dentro de la Cristiandad. Además, se trata de una advocación religiosa muy vinculada a los Habsburgo.

\subsection{Estudios iconográficos}

En este apartado no pretendemos realizar un ensayo bibliográfico sobre las publicaciones relativas a la Inmaculada Concepción desde la Historia del Arte, pues es una empresa prácticamente inabarcable ${ }^{32}$. Lo que aquí debemos subrayar es la forma en que la representación plástica devocional es vehículo de trasmisión de discursos que pueden ser de muy variado tipo. Entender el mensaje de las imágenes solo es el primer paso; de ahí en adelante hay que cotejarlas, establecer factores de variación y significados en su contexto. En definitiva, no se trata únicamente de hacer que las representaciones sean comprensibles para nosotros, sino que también sean comprensibles en su propia época.

Un mismo tipo de fuente icónica puede transmitir discursos diferentes. Exponemos aquí tres trabajos que ejemplifican la riqueza que nos pueden proporcionar las fuentes visuales para el tema de la Inmaculada Concepción. Por ejemplo, las estampas durante el siglo XVII podían servir para mover a los fieles a adoptar actitudes piadosas y difundir una particular devoción o determinados planteamientos teológicos, como ha estudiado Rosa Margarita Cacheda Barreiro ${ }^{33}$. Asimismo, también podían articular un discurso político propagandístico, como señala Juan Isaac Calvo Portela al estudiar la aparición de la Monarquía Hispánica en las estampas religiosas de la Inmaculada ${ }^{34}$. Lógicamente, que el medio sea el mismo no significa que los destinatarios sean iguales: en el primer caso, la iconografía religiosa era bien conocida por toda la sociedad del siglo XVII; pero al segundo solo podrían acceder un estrato culto bastante reducido. Las estrategias iconográficas -podríamos decir también simbólicas, pero preferimos reservar este concepto para la antropologíatambién son diferentes: las segundas estampas tienen una composición mucho más elaborada que las primeras. Geográficamente las estrategias asimismo cambian: la defensa de la Inmaculada en los territorios de Indias por la monarquía tenía su propia retórica, cuya especificidad ha analizado Álvaro Pascual Chene ${ }^{35}$.

La iconografía es también una fuente privilegiada para la etnohistoria o la historia antropológica. Así trata Luisa Accati las pinturas del Oratorio della Purità de Udine, donde todavía hoy es un lugar de celebración de la ceremonia del Matrimo-

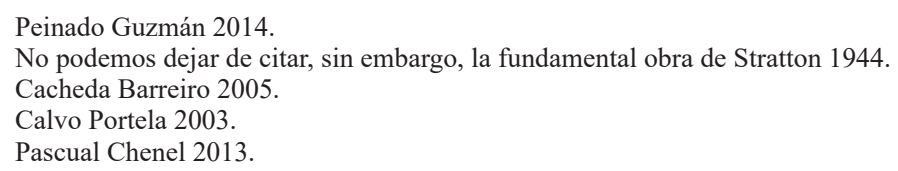


nio $^{36}$. La autora subraya la diferencia entre las palabras de la liturgia, que parecen sancionar una unión entre iguales, y las imágenes que rodean la celebración en el Oratorio, que ponen el acento sobre la novia. El cuadro del altar es una Inmaculada de Tiépolo, pues a esta advocación religiosa se dedica el templo, produciéndose un claro paralelismo entre la futura esposa y la Virgen. Pero se trata de una imagen construida desde un discurso masculino: es el sacrificio de la novia, que acepta caer del estado de mayor perfección del catolicismo, la virginidad, y esta «caída», para ser socialmente aceptada, ha de ser sublimada a través del símbolo religioso, que contrapone a la unión entre hombre y mujer la de mujer e hijo. Las frescos laterales de Tiepolo que hay en el oratorio insisten en este planteamiento, que es herencia del Concilio de Trento. Además de pintura religiosa, hay pintura de tema mitológico; pero en todos los casos, se representa el relevo de los personajes adultos y paternos por las figuras jóvenes (los siete hermanos con su madre ante el tirano Antíoco, David y Goliat, Jesús ante los doctores). Además del componente religioso, estas representaciones tienen un aspecto político: el poder temporal del padre está en una posición de subordinación frente al poder espiritual representado por los hijos, y entre ambos se sitúa la figura de la madre identificada con la Inmaculada.

\subsection{Historia de las mentalidades, antropología religiosa y estudios de género}

Ya desde la historia de las mentalidades la hispanista Estrella Ruiz-Gálvez Priego se ha interesado por la razón de que una disputa estrictamente teológica trascendiese los límites de las cátedras y se proyectase con tanta fuerza en la sociedad hispánica de la Edad Moderna ${ }^{37}$. Según señala la autora, varios elementos clave de este misterio tenían una transcripción social evidente en su época, y se pueden rastrear a partir de múltiples fuentes, tanto iconográficas como literarias. Por ejemplo, la definición de «mácula», que era «fallar» o faltar al compromiso dado, vinculaba al inmaculismo con la ética caballeresca, cuyos valores estaban aceptados por la sociedad en general. Otro aspecto, como la trasmisión de la mácula, que se pensaba a través de la sangre, tenía una formulación devocional precisa en la veneración a la Preciosa Sangre de Cristo, y una traducción social en la exclusión étnica con los estatutos de limpieza de sangre. Por otra parte, la proyección social del inmaculismo tiene también una formulación de género que reivindicaron las mujeres de la élite en clave de «firmeza femenina» y «triunfo de la feminidad». Desde la iconografía presente en las Descalzas Reales -foco inmaculista de gran peso por la presencia de Margarita de Austria- hasta la literatura de Maria de Zayas, la Inmaculada representaba la excelencia femenina en un mundo de hombres.

Esa misma disputa fue el punto de partida de los votos y juramentos inmaculistas, tanto en universidades como en corporaciones municipales, elemento que ha atraído la atención de algunos especialistas, ${ }^{38}$ al igual que los sermones. ${ }^{39}$ No obstante, se trata de publicaciones que se limitan a recoger los textos y trazar las coordenadas más elementales en donde estos se insertan, sin avanzar alguna interpretación de

Accati 1990. Vid. también Accati 2009.

Ruiz-Gálvez Priego 2006; Ruiz-Gálvez Priego 2008.

Marcos 1954; Gómez 1955; Pascual Martínez 1976; Polo Carrasco 1984; Polo Carrasco 1987; Bastero 1990; Vizuete Mendoza 2005.

39 Gómez López 1984; Cañizares del Rey 2015. 
calado. Una excepción de gran interés es la de los sermones en Nueva España, que manifestaban la adhesión de la élite criolla a la monarquía al compartir una misma devoción inmaculista - orientada por los últimos Habsburgo como un elemento compensatorio ante las dificultades que atravesaban y por el primer Borbón como una muestra de continuidad en la corona tras el cambio dinástico- y cuyo simbolismo acabó plasmado en la propia arquitectura novohispana. ${ }^{40}$

Las celebraciones son momentos propicios para el estudio antropológico, pues en ellas se despliegan multitud de símbolos (gestos, representaciones, hechos, palabras, etc., en definitiva, cualquier cosa que significa otra) a través de los cuales llegar a las concepciones que tenían los hombres y las mujeres del pasado. Sin embargo, a veces esto no se logra. En su estudio de la mascarada inmaculista que se produjo en Sevilla en noviembre de 1617 y que fue organizada por los plateros, María Jesús Sanz se queda en una simple narración del evento. ${ }^{41}$ Contando con fuentes sólidas, el artículo no trasciende la descripción de los disfraces y las imágenes que sacaron las cuadrillas. Por ejemplo, la de los negros y la de los caciques tienen una clara connotación étnica que no puede ser pasada por alto. Un análisis más completo habría puesto en relación los distintos elementos unos con otros, de forma que se estableciesen sus significados, y haber analizado en qué grado los distintos espectadores tenían acceso a estos.

De mucho más interés es la ponencia presentada por Luisa Accati al Primer Congrés d'Història de la Dona. De la casa a la fàbrica. La dona com a element de transformació social (s. V-XX), celebrado en 1986, que constituye un estudio a medio camino entre la antropología histórica y la historia de las mujeres. ${ }^{42}$ Partiendo de los trabajos del psicoanálisis sobre el sonambulismo, esta autora afirma que a través de este símbolo religioso las jóvenes tomaban conciencia del deseo sexual sin aceptar el dolor de la desfloración. La adolescente se identificaba con la Virgen, bella y joven como ella, y esta identificación le inducía a permanecer en ese estado de inocencia. Ello se explica porque, siguiendo a Freud, la mujer durante la pubertad experimenta un aumento del narcisismo primario, y en este momento la pérdida de la virginidad es una pérdida de poder. En última instancia, la Inmaculada servía a las jóvenes como modelo durante esa etapa de narcisismo primario, exaltando la conducta virtuosa frente a cualquier tipo de afirmación de otras capacidades, según el modelo de feminidad socialmente aceptado.

Por último, debemos destacar la aproximación que realiza Raúl Mínguez Blasco al tema de la Inmaculada en el siglo XIX..$^{43}$ Dos partes constituyen este trabajo: la proclamación dogmática como recurso dentro de una política más amplia de afirmación autoritaria de la Iglesia romana y la Inmaculada como símbolo de identidad nacional para el caso español. En cuanto a la primera parte, la Inmaculada frente al pecado establecía un paralelismo teológico claro con el Papa frente a la revolución, respaldado además en la retórica de la publicística católica por una «feminización simbólica» del Papa como virgen y madre que debía guardar su virginidad dentro de su casa, esto es, sus territorios, lo que legitimaba su poder temporal frente al proceso de unificación italiana. La segunda parte trata de la lectura nacionalista y reacciona-

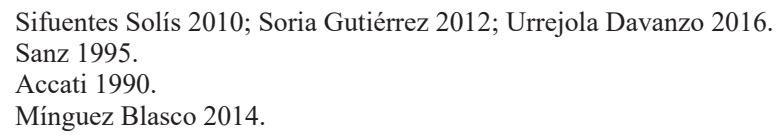


ria del dogma de la Inmaculada que se hizo en España por parte de obispos, carlistas y neocatólicos en el momento en que se introducía en los debates constitucionales del Bienio Progresista la tolerancia religiosa, y que, para este autor, sentaría las bases de lo que posteriormente fue el nacional-catolicismo.

\section{Conclusión}

Este recorrido centrado en una advocación religiosa de gran arraigo en España pone de manifiesto el desarrollo de los estudios históricos sobre la Iglesia y la religión en nuestro país. En las últimas décadas se ha dado el paso definitivo desde una historia de las instituciones eclesiásticas a una historia social y cultural del fenómeno religioso. Ello ha venido motivado tanto por el proceso constante de secularización experimentado, como por la propia evolución de la historia dentro del conjunto de las ciencias sociales y su creciente diálogo con algunas de estas, como la sociología o la antropología. Asimismo, nuevas perspectivas de estudio han multiplicado las formas de aproximarse a la religión y a sus múltiples dimensiones. Todo esto hace que la historia tenga un lugar dentro de las ciencias de las religiones y, sobre todo, que el diálogo interdisciplinar en este campo del saber sea cada vez más imprescindible.

Por otro lado, el tema de la Inmaculada Concepción puede ser revisitado desde la historiografía a la luz de nuevas dimensiones. Así, mientras que ha sido un objeto de estudio preferente para los historiadores modernistas, apenas se ha abordado para la Edad Contemporánea, que es precisamente cuando se produce la proclamación dogmática de la Inmaculada (1854). En este sentido, es deseable una profundización desde la historia de las mujeres que analice esta advocación mariana como símbolo trasmisor de unas valores de feminidad en el siglo XIX, y que intente reconstruir la génesis del modelo de mujer burguesa desde raíces católicas, superando la mera extrapolación del «ángel del hogar» anglosajón a países mediterráneos como España, Francia o Italia.

\section{Bibliografía}

C. M. Abad, «Preparando la embajada concepcionista de 1656. Estudio sobre cartas inéditas a Felipe IV y a Alejandro VII», Miscelánea Comillas 20 (1953) 25-58.

L. Accati, «Débito conyugal e interés eclesiástico», Historia Social 7 (1990a) 5-18.

L. Accati, «I mediatori del sacro», Acta Histriae 17/1-2 (2009) 239-250.

L. Accati, «La política dei sentimenti: l'Immacolata Concezione fra '600 e '700», DUODA. Papers de Treball 1 (1990b) 23-40.

G. Alonso, La nación en capilla. Ciudadanía católica y cuestión religiosa en España, 17931874, Granada, 2014.

J. Álvarez Junco, Mater Dolorosa. La idea de España en el siglo XIX, Barcelona, $2015^{13}$.

B. Anderson, Comunidades imaginadas. Reflexiones sobre el origen y la difusión del nacionalismo, (trad. esp.), México, 1993.

S. Arbolí y Faraúdo, La Eucaristía y la Inmaculada: devoción española, Sevilla, 1895.

A. Ballerini, Questio an S. Ildefonsus Episcopus toletanus Conceptae Virginis Festum in Hispanis instituerit, Roma, 1856. 
A. Ballerini, Sylloge monumentorum ad mysterium Conceptionis Immaculatae Virginis Deiparae, 2 ts., Roma, 1854-56.

J. L. Bastero, «El juramento inmaculista de la Real y Pontificia Universidad de México (1619). Edición del texto y comentario», en Evangelización y teología en América (siglo XVI): X Simposio Internacional de Teología de la Universidad de Navarra, t. II, Pamplona, 1990, 1089-1109.

Z. Box, España, año cero. La construcción simbólica del franquismo, Madrid, 2010.

P Broggio, «Teologia, ordini religiosi e rapporti politici: la questione dell'Immacolata Concezione di Maria tra Roma e Madrid (1614-1663)», Hispania Sacra 65/extra 1 (2013) 255-281.

R. M. Cacheda Barreiro, «Dogma, ideología y devoción. La Inmaculada Concepción a través de las estampas del siglo XVII», en F. J. Campos (ed.), La Inmaculada Concepción en España: religiosidad, historia y arte, t. II., San Lorenzo de El Escorial, 2005, 845-868.

J. I. Calvo Portela, «La Monarquía Hispánica defensora de la Inmaculada Concepción a través de las estampas del siglo XVII», Anales de Historia del Arte 23 (2003) 155-168.

F. J. Campos (ed.), La Inmaculada Concepción en España: religiosidad, historia y arte, 2 ts. San Lorenzo de El Escorial, 2005.

L. Cano, «Reinaré en España». La mentalidad católica a la llegada de la Segunda República, Madrid, 2009.

V. Cañizares del Rey, «La belleza de María Inmaculada: sermón pronunciado en Lajosa el día 31 de mayo de 1896», Lucensia: Miscelánea de Cultura e Investigación 26/51 (2015) 187-194.

P. Castañeda Delgado - M. J. Cociña y Abella (eds.), La Inmaculada y Sevilla, Córdoba, 2007.

B. S. Castellanos de Losada, Reseña histórica de los fundamentos, devoción, controversia y festividad de la Inmaculada Concepción de María Santísima, Madrid, 1855.

M. C. Contel Barea, «Junta de la Inmaculada Concepción de la Virgen», en J. A. Ferrer Benimeli (ed.), Relaciones Iglesia-Estado en Campomanes, Madrid, 2002, 181-208.

Diario de las discusiones y actas de las Cortes de Cádiz, t. IX, Cádiz, 1811.

J.-D. Durand, «Le parcours de l'histoire religieuse dans l'evolution culturelle eurpéene», Lusitania Sacra 21 (2009) 39-62.

J. Escalera, «Pérez, Nazario», en Ch. E. O’Neill - J. M. a Domínguez (eds.), Diccionario histórico de la Compañía de Jesús, t. III, Roma-Madrid, 2001, 3.090-3.091.

Á. Ganivet, Idearium español. El porvenir de España, Granada, 1897 (reimpr. Madrid, $\left.1970^{8}\right)$.

A. García Pérez, El Patronato de la Inmaculada en la Infantería española, Málaga, 1912.

A. García Pérez, Glorias de María Inmaculada en los hechos de armas más sobresalientes del Ejército español, Madrid, 1905.

V. Gebhardt, Historia General de España y de sus Indias desde los tiempos más remotos hasta nuestros dias, t. II, Madrid-Barcelona-La Habana, 1864.

O. Gómez, «Juramentos concepcionistas de las universidades españolas en el siglo XVII», Archivo Ibero-Americano 15/59-60 (1955), 867-1045.

J. Gómez López, «El 'Conorte' de sor Juana de la Cruz y su sermón sobre la Inmaculada Concepción de María», Hispania Sacra 36/74 (1984) 601-627.

Th.-M-J. Gousset, La croyance générale et constante de l'Église touchant l'Immaculée Conception de la Bienhèreuse Virge Marie, París, 1855.

M. A. Gravois, De ortu et progressu cultus ac festi Immaculati conceptus Beatae Dei Genetris Virginis Marie, Luca, 1762. 
C. Gutiérrez, «España por el dogma de la Inmaculada. La embajada a Roma de 1659 y la bula ‘Sollicitudo' de Alejandro VII», Miscelánea Comillas 24 (1955) 13-480.

E. Hobsbawm - T. Ranger (eds.), La invención de la tradición, (trad. esp.), Barcelona, 2002. Ph. Jenkins, The Great and Holy War. How World War I became a Religious Crusade, San Francisco, 2014.

M. Jugie, L'Immaculée Conception dans l'Écriture Sainte et dans la tradition orientale, Roma, 1952.

C. Langlois - A. Vauchez, «L'histoire religieuse», en F. Bédarida (ed.), L'histoire et le métier d'historien en France, 1945-1995, París, 2009, 313-323.

V. Laurent, «L'Oeuvre scientifique du R. P. Martin Jugie», Revue des études byzantines 11 (1953) 19-32.

F. Marcos Rodríguez, «La Universidad de Salamanca y la Inmaculada», Salmanticensis 1/3 (1954), 539-605.

J. F. Masdeu, Historia crítica de España y de la cultura española, t. XI, Madrid, 1792.

M. Menéndez Pelayo, Varia, ed. de E. Sánchez Reyes, t. I, Santander, 1956.

J. Meseguer, «La Real Junta de la Inmaculada Concepción (1616-1817/1820)». Archivo Ibero-Americano 59-60 (1955) 627-651.

R. Mínguez Blasco, «Las múltiples caras de la Inmaculada: religión, género y nación en su proclamación dogmática (1854)», Ayer 96 (2014) 39-60.

F. Montero, «De la historia eclesiástica a la historia religiosa. Una trayectoria historiográfica», Historia Contenporánea 51 (2015) 487-506.

Novísima Recopilación, t. I, Madrid, 1805.

J. M. Oller, España y la Inmaculada, Madrid, 1905.

Á. Pascual Chenel, «Fiesta sacra y poder político: la iconografía de los Austrias como defensores de la Eucaristía y la Inmaculada en Hispanoamérica», Hipogrifo. Revista de Literatura y Cultura del Siglo de Oro 1/1 (2013) 57-86.

L. Pascual Martínez, «Efemérides murcianas: el juramento inmaculista de la ciudad el año 1623, Monteagudo: Revista de literatura española, hispanoamericana y teoría de la literatura 56 (1976), 11-17.

J. A. Peinado Guzmán, «La monarquía española y el dogma de la Inmaculada Concepción: fervor, diplomacia y gestiones a favor de su proclamación en la Edad Moderna», Chronica Nova 40 (2014) 247-276.

R. Pérez Fernández, La Inmaculada Concepción, Patrona de la Infantería Española, Salamanca, 1937.

P. L. Pérez Frías, «Advocaciones marianas de Gloria en la milicia española. Una devoción inmemorial», en F. J. Campos (ed.), Advocaciones marianas de Gloria, San Lorenzo de El Escorial, 2012, 35-52.

P. L. Pérez Frías, «Las élites militares de Alfonso XIII y la Inmaculada Concepción: el caso de Antonio García Pérez», en F. J. Campos (ed.), La Inmaculada Concepción en España: religiosidad, historia y arte, t. I, San Lorenzo de El Escorial, 2005, 305-326.

N. Pérez, La Inmaculada y España, Santander, 1954.

B. Plazza, Causa Immaculatae Conceptionis Sanctissimae Matris Dei Dominae Nostrae, Palermo, 1747.

J. Polo Carrasco, «Los juramentos inmaculistas de la Universidad, Cabildo Catedralicio y Ciudad de Zaragoza (1617-1619)», Cuadernos de Historia Jerónimo Zurita 49-50 (1984) 87-117.

J. Polo Carrasco, Los juramentos inmaculistas de Zaragoza (1617-1619): estudio críticodocumental, Zaragoza, 1987. 
J. M. Pou i Martí, Embajadas de Felipe III a Roma pidiendo la definición de la Inmaculada Concepción de María, Vich, 1932.

F. Ramírez de Luque, Historia de los hechos y escritos del clero secular en defensa y honor de la Concepción Inmaculada de María Santísima, Madrid, 1776.

J. Roca y Cornet, María Inmaculada. Recuerdos históricos y afectuosos desahogos, Barcelona, 1856.

C. Ros, La Inmaculada y Sevilla, Sevilla, 1994.

C. Ros, Salve Madre. La Inmaculada y España, Madrid, 2013.

E. Ruiz-Gálvez Priego, «'Sine Labe'. El inmaculista en la España de los siglos XV a XVIII», Revista de dialectología y tradiciones populares 62/2 (2008) 197-241.

E. Ruiz-Gálvez Priego, «La Inmaculada: emblema de la firmeza femenina», Arenal 13/2 (2006) 291-310.

M. J. Sanz, «El problema de la Inmaculada Concepción en la segunda década del siglo XVII. Festejos y máscaras: el papel de los plateros», Laboratorio de Arte 8 (1995) 73-101.

A. Serrano Durán, Historia del Patronato de la Inmaculada Concepción sobre el Arma de Infantería, Toledo, 1905.

M. A. Sifuentes Solís, «La sermonaria novohispana y su influencia en la arquitectura religiosa de Aguascalientes: prácticas de lectura y simbolismo mariano en el Camarín de la Virgen (1792-1797)», Hib: Revista de Historia Hispanoamericana 3/2 (2010) 90-123.

A. Soria Gutiérrez, «Lengua, ojos y oídos de un sermón mariano en defensa de la Inmaculada Concepción», en B. López de Mariscal - N. J. Dyer (coords.), El sermón novohispano como texto de cultura: ocho estudios, Nueva York, 2012, 107-127.

S. L. Stratton, The Immaculate Conception in Spanish Art, Cambridge, 1944.

B. Urrejola Davanzo, «Notas sobre la Inmaculada Concepción en sermones novohispanos», Magallánica. Revista de Historia Moderna 3/5 (2016) 99-122.

I. Vázquez, Las negociaciones inmaculistas en la Curia romana, Madrid, 1957.

J. C. Vizuete Mendoza, «Voto, juramento y fiesta de la Inmaculada en la Universidad de Toledo», en F. J. Campos (ed.), La Inmaculada Concepción en España: religiosidad, historia y arte, t. I, San Lorenzo de El Escorial, 2005, 327-360.

M. Zalba, «Ballerini, Antonio», en Ch. E. O’Neill - J. M. ${ }^{a}$ Domínguez (eds.), Diccionario histórico de la Compañia de Jesús, t. I, Roma-Madrid, 2001, 330. 